\title{
Comparing a small gravel-less perforated pipe leach fields (GPPLF) to a medium one in treating domestic sewage
}

\author{
Yiheng Yang ${ }^{1 *}$, Chengduan Wang ${ }^{2}$, Zhenhua Dang ${ }^{1}$ \\ ${ }^{1}$ School of Environment and Resources, Southwest University of Science and Technology, Mianyang, China; \\ *Corresponding Author: 173795380@qq.com \\ ${ }^{2}$ Sichuan University of Science and Engineering, Zigong, China
}

Received 20 January 2012; revised 15 February 2012; accepted 29 February 2012

\begin{abstract}
There were obvious differences between a medium gravel-less perforated pipe leach fields and a small system in the treatment of demestic sewage with the change of influent quality. In small system, COD removal rate was $91 \%$, ammonia nitrogen removal rate was $90 \%$, total nitrogen was $\mathbf{5 8 \%}$. In medium system, COD removal rate was $86.07 \%$, ammonia nitrogen removal rate was $45.3 \%$, and total nitrogen was 48.2\%. This paper studied on the differences. Its main reasons were as follows: differences in opening rate (perforated area account of the total area in infiltration pipe), air flow conditions, exterior environment, and wastewater distribution. Considering those problems, solutions and applications for the development of GPPLF are given.
\end{abstract}

Keywords: Gravel-Less Perforated Pipe Leach Fields; Pollutants Removal Rate; Comparing; Component; Formatting; Style; Styling; Insert

\section{INTRODUCTION}

Grave-less subsurface wastewater infiltraten system has been widely used, which is applied underground in rural areas of the United States, Canada, Japan and many other countries. It is an ecological technology of sewage treatment by making full use of the soil microorganism, microbes and plant roots and the physical and chemical action of soil. In particular, it is one of the best solutions for sewage treatment in rural areas where people live remotely [1,2]. Gravel-less perforated pipe leach fields is developed and improved based on traditional perforated pipe leach fields, and the infiltration pipe is directly set in the soil without external fabric. The collection area is sand (particle size is $0.1-2 \mathrm{~cm}$ ), with outlet pipe set up under it [3].

The good aerobic environment and better distribution of water can increase the pollutants removal rate in perforated pipe leach fields. And in this paper, the design differences between small system and medium system is studied, and solutions and applications for the development of GPPLF was given.

\section{MATERIALS AND METHODS}

\subsection{Small System}

The width, length and height of the small system was $30 \mathrm{~cm}, 60 \mathrm{~cm}$ and $140 \mathrm{~cm}$ respectively. Collecting area was set in the bottom $20 \mathrm{~cm}$ of the system where infilled with sand (particle size is $0.1-2 \mathrm{~cm}$ ), and above the sand filled with sandy loam for experiment, then grow plants in sandy loam. In infiltration pipe, all around pipe wall was perforated. The diameter of the micropore in the infiltration pipe was $4 \mathrm{~mm}$, and the infiltration pipe is DN200, as shown in Figure 1.

\subsection{Medium System}

There were 8units in medium system. The width, length and height of each unit was $140 \mathrm{~cm}, 140 \mathrm{~cm}$ and $130 \mathrm{~cm}$ respectively, and in the bottom $20 \mathrm{~cm}$ of each unit was collecting area where filled sand (particle size is $0.1-2 \mathrm{~cm}$ ). And above the sand filled with sandy loam for experiment, then grow plants in sandy loam. Outlet pipe, which collected and discharged the effluent, was at the bottom of the system. The diameter of infiltration pipe in Unit 1-4 and 5-8 were respectively DN160 and DN200, as shown in Figure 2. The opening rate is 15\% (perforated area accounts for $15 \%$ of the total area), and the opening angle are $95^{\circ}-170^{\circ}$ and $190^{\circ}-265^{\circ}$. In the infiltration pipe, the diameter of the micropore was 4 $\mathrm{mm}$. 

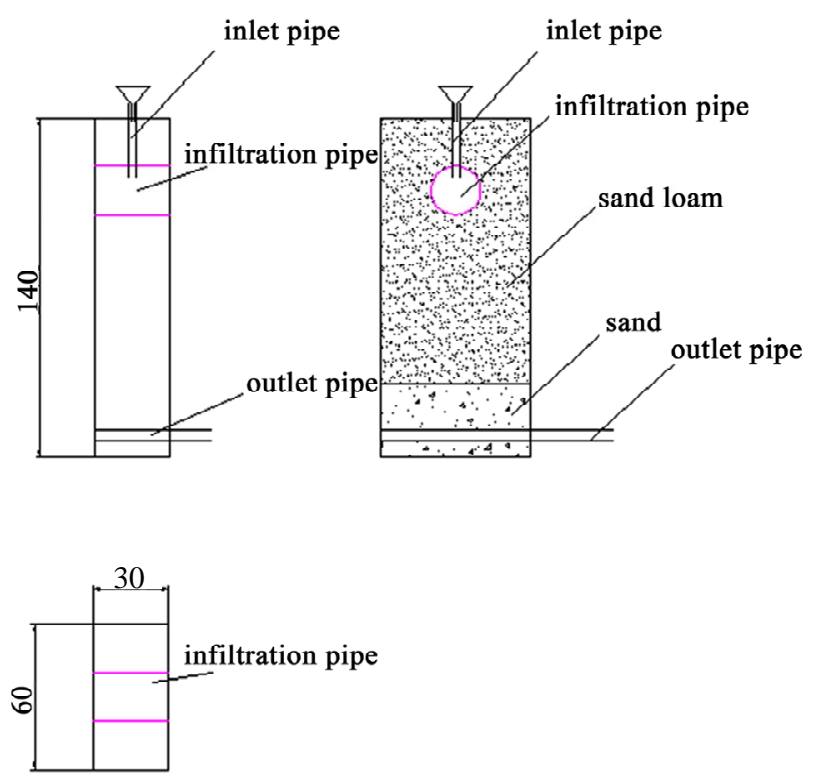

Figure 1. Small system (cm).
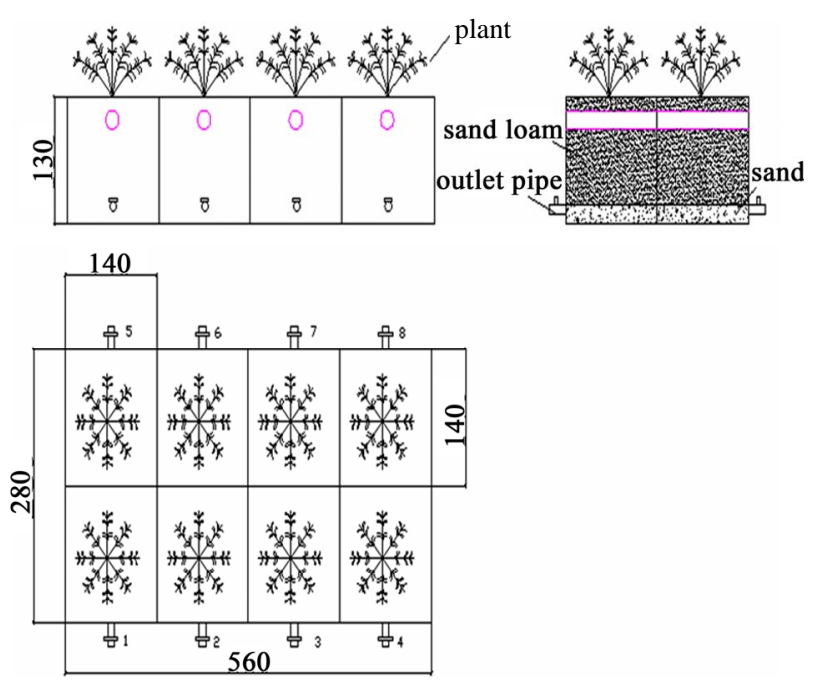

Figure 2. Medium system (cm).

\subsection{Influent Quality}

There were influent quality, as shown in Table 1.

\section{RESULTS AND DISCUSSIONS}

\subsection{Results}

The hydraulic load was $3.3 \mathrm{~cm} / \mathrm{d}$ in small system, and in medium system it was $3.189 \mathrm{~cm} / \mathrm{d}$. Hydraulic load was almost equal, while the disparity of the pollutant removal rates was very obvious. In the medium system, the pipe diameter of infiltration pipe in Unit 1-4 and 5-8 were respectively DN160 and DN200.We average data in the Unit 1-4 and 5-8 respectively, as shown in Figures 3-14.
Table 1. Influent quality.

\begin{tabular}{ccccc}
\hline quality & $\mathrm{COD}(\mathrm{mg} / \mathrm{L})$ & $\mathrm{BOD}_{5}(\mathrm{mg} / \mathrm{L})$ & $\mathrm{SS}(\mathrm{mg} / \mathrm{L})$ & $\mathrm{pH}$ \\
\hline wave range & $280-700$ & $130-300$ & $100-300$ & $7-9$ \\
quality & $\mathrm{NH}_{3}-\mathrm{N}(\mathrm{mg} / \mathrm{L})$ & $\mathrm{TN}(\mathrm{mg} / \mathrm{L})$ & $\mathrm{TP}(\mathrm{mg} / \mathrm{L})$ & \\
wave range & $25-70$ & $35-95$ & $3-11$ & \\
\hline
\end{tabular}

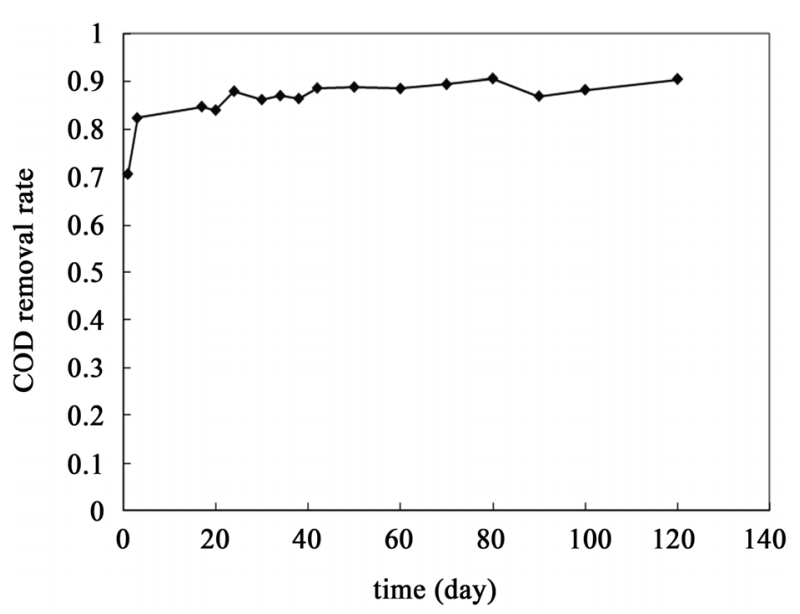

Figure 3. COD removal rate.

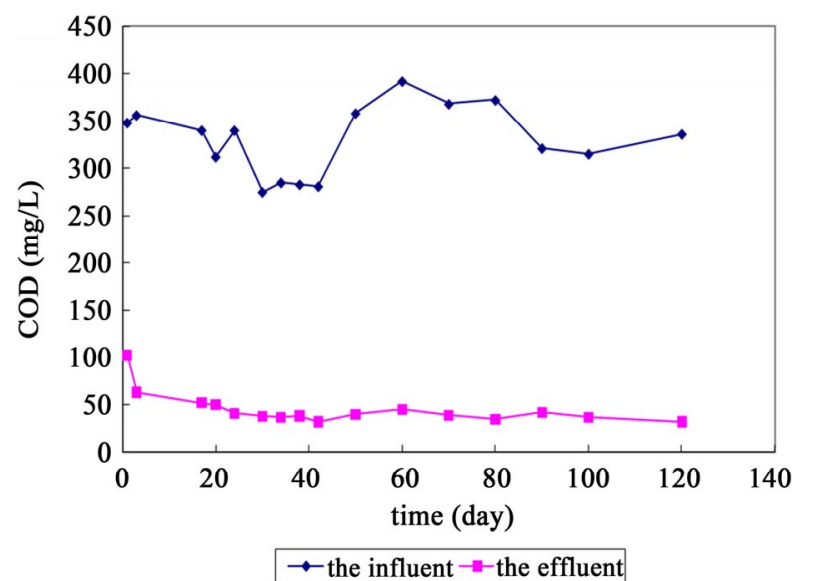

Figure 4. COD in the influent and the effluent.

\subsubsection{Small System}

In small system, COD removal rate was 91\%, ammonia nitrogen removal rate was $90 \%$, total nitrogen was $58 \%$, as shown in Figures 3-8.

\subsubsection{Medium System}

In medium system, COD removal rate was $86.07 \%$, ammonia nitrogen removal rate was $45.3 \%$, and total nitrogen was 48.2\%, as shown in Figures 9-14.

We can conclude by comparing small and medium test that the pollutant removal rate of the small test remarkably exceeds that of the medium test. The removal rate in Unit 1-4 was better than Unit 5-8. Because the contact 


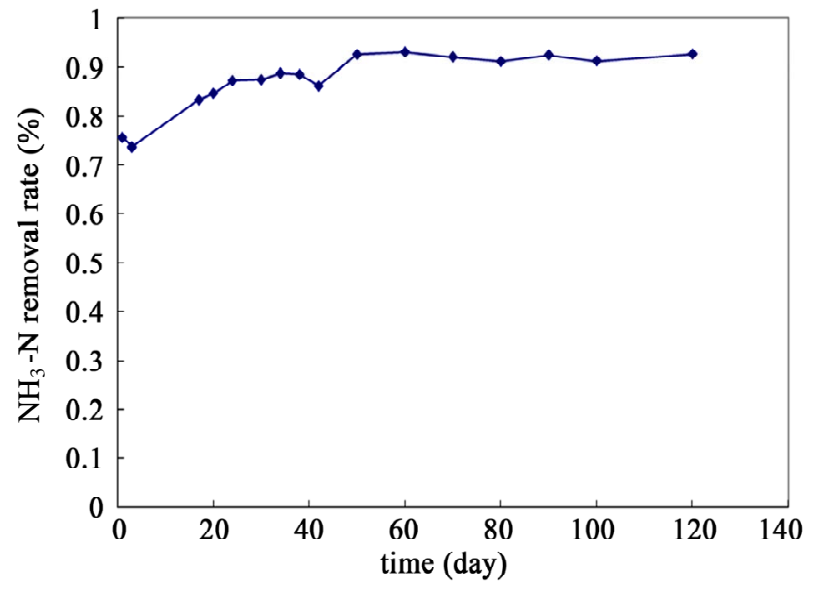

Figure 5. $\mathrm{NH}_{3}-\mathrm{N}$ removal rate.

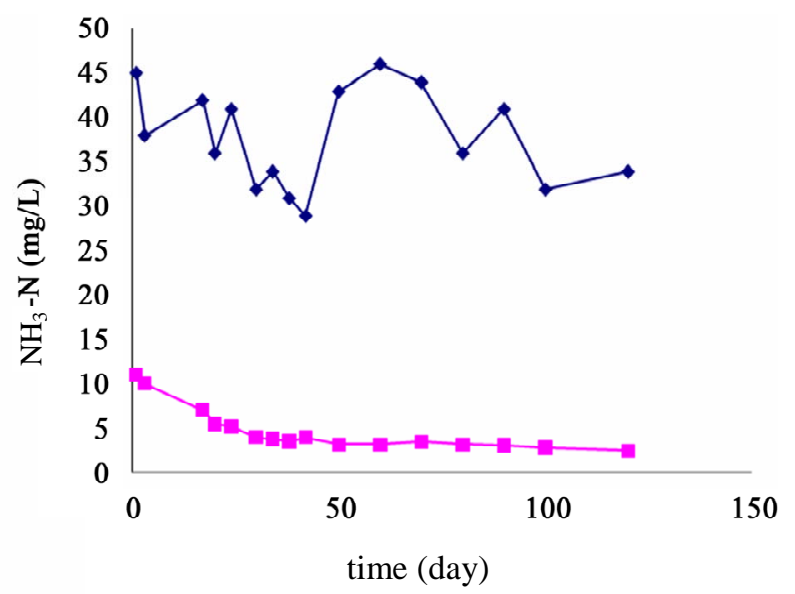

\section{$\rightarrow$ the influent $\rightarrow-$ the effluent}

Figure 6. $\mathrm{NH}_{3}-\mathrm{N}$ in the influent and the effluent.

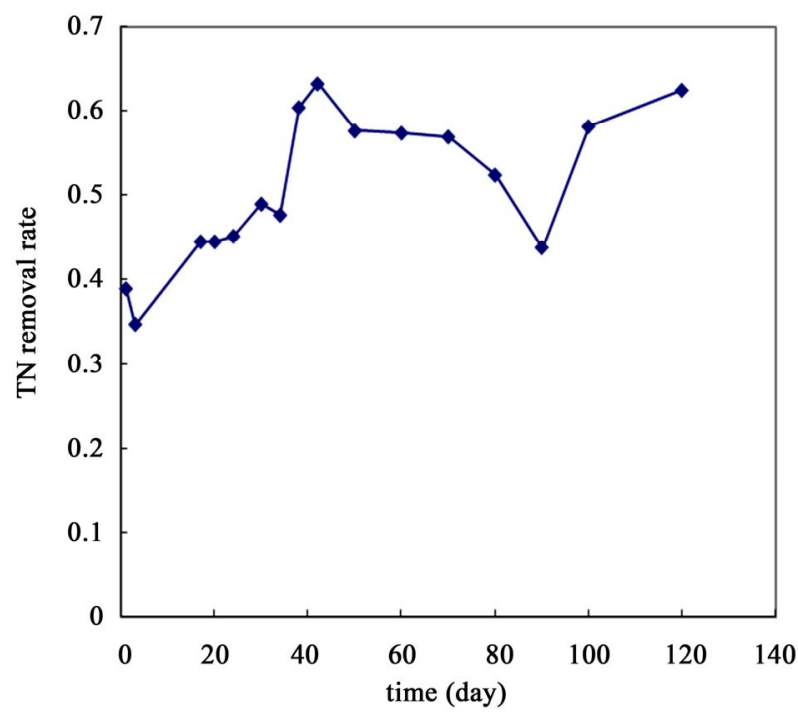

Figure 7. TN removal rate.

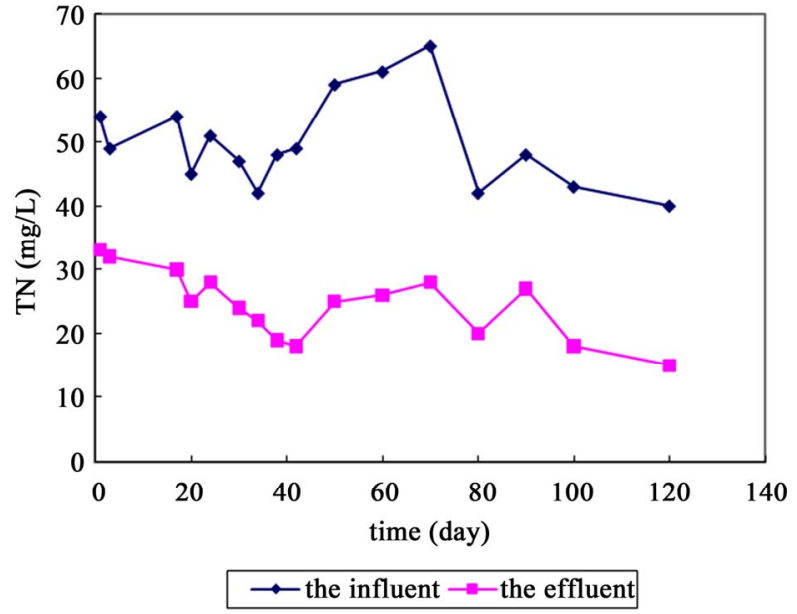

Figure 8. NT in the influent and the effluent.



Figure 9. COD in the influent and the effluent.

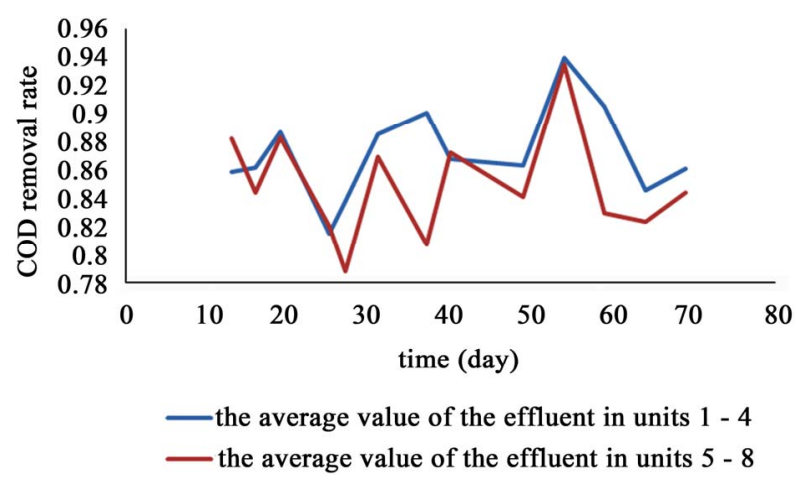

Figure 10. COD removal rate.

area of pipe wall, soil interface and the air will be enlarged in DN200 pipe, which was conducive to the improvement of aerobic environment and sewage welldistributed in the soil around the infiltration pipe.

The organic nitrogen in sewage flow into soil. Then, it is converted into other organic matter by ammonifier. The remaining nitrogen is released into the form of ammonia, while the nitrogen exists in the form of $\mathrm{NH}^{4+}$ in water is absorbed by soil, and then it is rapidly oxidized 


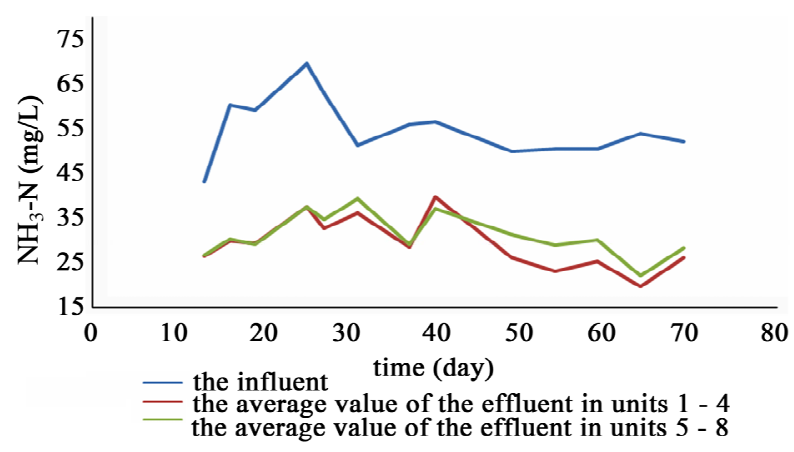

Figure 11. $\mathrm{NH}_{3}-\mathrm{N}$ in the influent and the effluent.

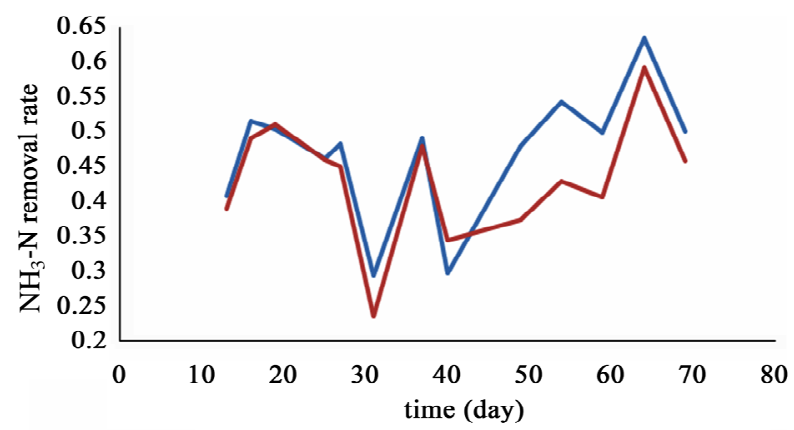

- the average value of the effluent in units $1-4$

- the average value of the effluent in units 5 - 8

Figure 12. $\mathrm{NH}_{3}-\mathrm{N}$ removal rate.

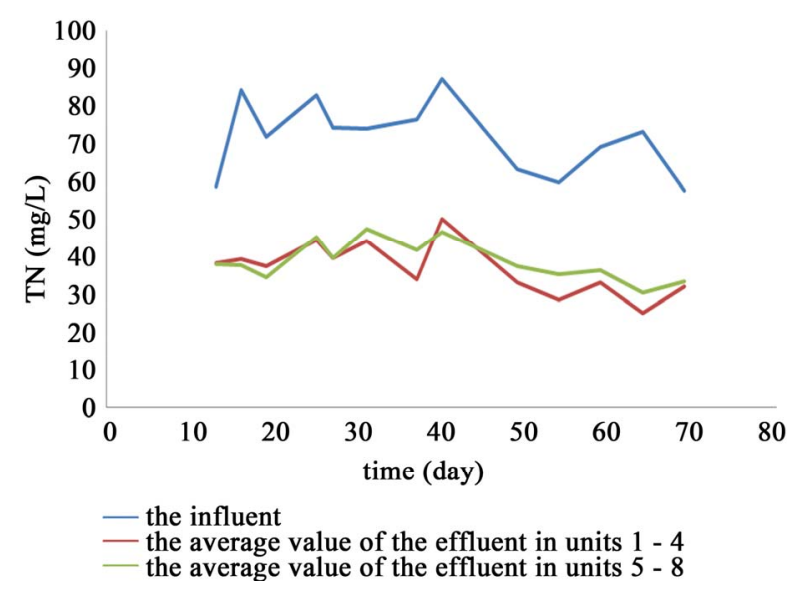

Figure 13. TN in the influent and the effluent.

to $\mathrm{NO}_{3}$ by nitrifying bacteria, which is nitrification process $[4,5]$. The result shows that the nitrification in small system is more complete than that in the medium system. Which means the improvement of aerobic environment in system is the most important.

The reasons of the differences and relevant improvement measures are the follows.

\subsection{Difference in Opening Rate}

If the aerobic condition of surface soil is very good, it

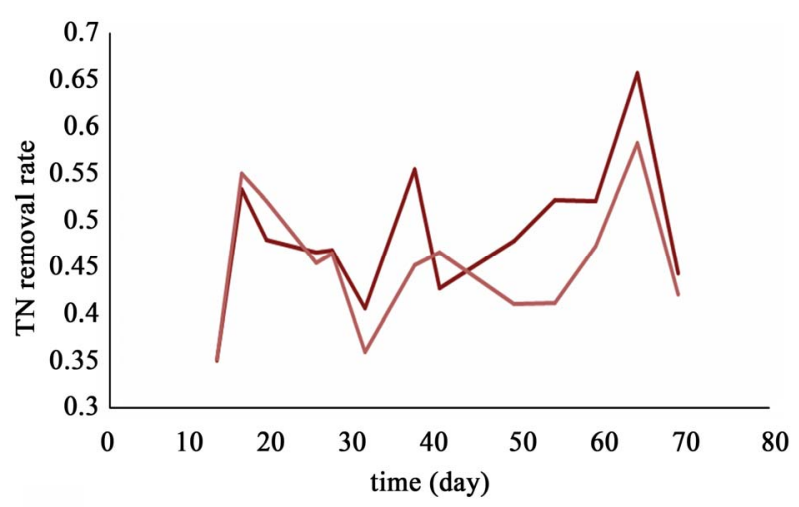

— the average value of the effluent in units $1-4$

- the average value of the effluent in units $5-8$

Figure 14. TN removal rate.

will be beneficial for the growth of aerobic bacteria and nitrifying bacteria. In a small system, all around infiltration pipe wall was perforated, the opening rate was $20 \%$ (perforated area account for $20 \%$ of the total area). However, in medium system, the opening rate was 15\% (perforated area account for $15 \%$ of the total area), the opening angle were $95^{\circ}-170^{\circ}$ and $190^{\circ}-265^{\circ}$. Improving aerobic environment in the soil around the infiltration pipe could prevent clogging [6-8]. In infiltration pipe, the diameter of the micropore was also $4 \mathrm{~mm}$. When the opening rate was $20 \%$, the contact area of pipe wall, soil interface and the air was enlarged, which is conducive to the improvement of aerobic environment in the soil around the infiltration pipe, thus contributing to nitrification and the release of ammonia. Therefore, the removal rate of pollutants in a small system is higher than that of the medium system. Since the small system is often placed in a shed, the rainstorm weather's impact on the system is not taken as an affecting factor. To achieve the best treatment effect, it is better choose $20 \%$ opening rate. Whereas the medium system was set outside, we need to take into account the impact of bad weather on the system, so the upper side of infiltration pipe remains closed so as to keep the soil above the infiltration pipe from entering it together with the rainwater or even clog it in rainstorm. When the GPPLF is operated on a large scale, we must take into consideration the rainstorm's impact on the system. Considering the above-mentioned two factors, we need to increase the opening rate on the premise of the system's normal operation. The concrete measure is to punch micropore intensively and closely in the lower side of the infiltration pipe so as to enlarge the contact area of pipe wall, soil interface and the air. As shown in Figure 15.

\subsection{Difference in Air Flow Conditions}

The small system had one water inlet pipe, above 


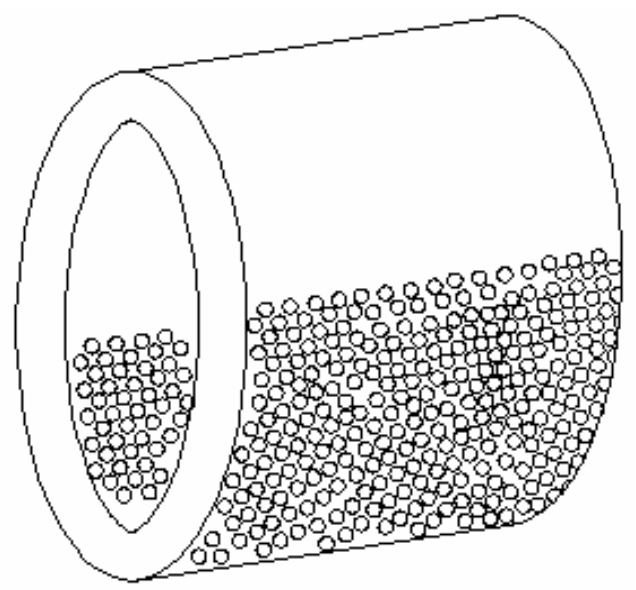

Figure 15. Infiltration pipe.

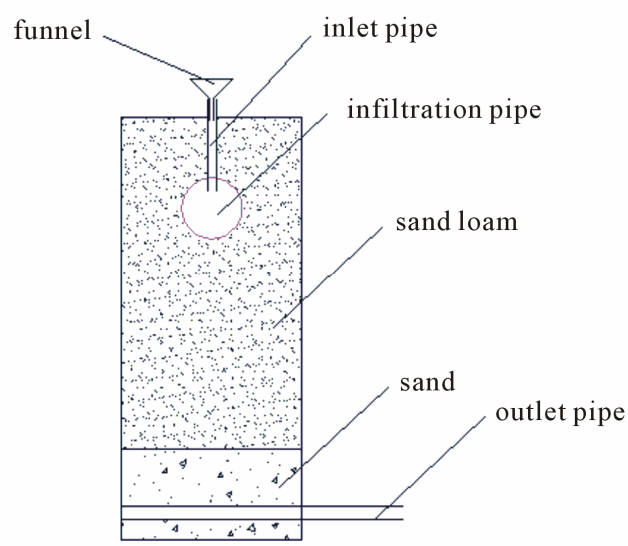

Figure 16. Air flow conditions in small system.

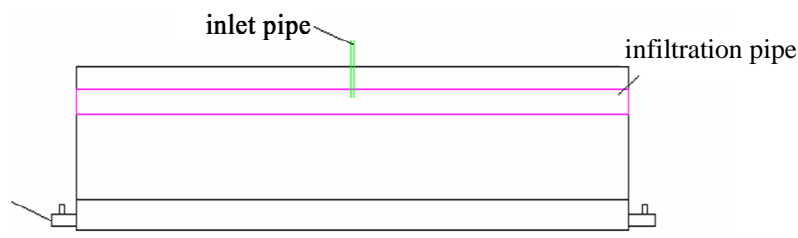

Figure 17. Air flow conditions in medium system.

which was a funnel, and inflow sewage by people. The inlet pipe was usually open. This is shown in Figure 16.

While the medium system also had an inlet pipe, and pumped domestic sewage. The inlet pipe was usually closed, and both side of infiltrate pipe were closed, as shown in Figure 17. So when it comes to the air flow condition, the small system was better than medium one. Improving air flow conditions can make aerobic environment in the soil around the infiltration pipe. It can make GPPLF achieve good denitrification effect to prevente clongging [9-11]. Both side of infiltrate pipe were closed, so the air flow conditions are not good. To improve soil aerobic environment and achieve good denitrification effect, hereby we improve the system below as

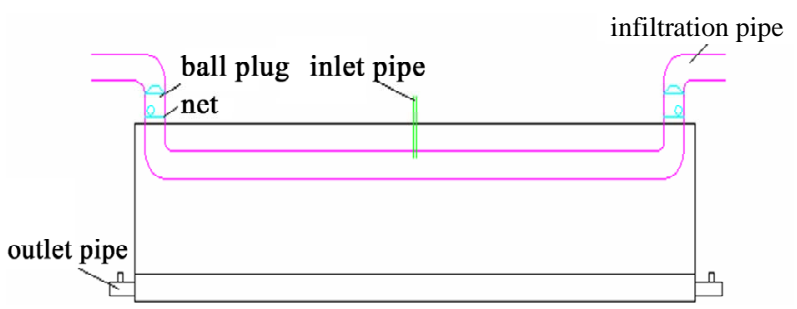

Figure 18. To improve air flow conditions medium system.

shown in Figure 18. Water level rises when water enters, and the ball valve floats up. Then, it closes. When the sewage inflow process is finished, the water level drops, the ball valve falls down. Then, it opens. And the air flows naturally. The shape of $\mathrm{Z}$ is designed to prevent solid waste from dropping into infiltrate pipe. Opening direction of the mouth of pipe is predominant wind direction and its opposite direction. It is beneficial for air flow conditions.

\subsection{Difference in Exterior Environment}

There was a shed on the small system .But the medium system was set on the playground, and there was no shed on it. Therefore, the impact of bad weather needs to be taken consideration. Pollutants removal rate in bad weather is lower than the average level. To solve it, we could set up open channel. At the end of open channel, there should be a sedimentation tank. Then, the soil washed down by rain can be collected. The effluent could be discharged, and the soil could be recycled in GPPLF.

\subsection{Difference in Wastewater Distribution}

Some scholars have also pointed that hydraulic properties of artificial wetland such as hydraulic retention time, hydraulic conductivity, water capacity, water flow patterns and other factors are all important factors to degrade pollutants [12-15]. The width and length of small system were respectively $30 \mathrm{~cm}$ and $60 \mathrm{~cm}$, the heights was $140 \mathrm{~cm}$. In a medium system, the width, length and height of each unit respectively was $140 \mathrm{~cm}, 140 \mathrm{~cm}$ and $130 \mathrm{~cm}$. Although the diameter of infiltration pipe were the same, the size of a small system was far smaller than that of a medium system. So, in terms of the differences in waste-water distribution, the distribution in small system was better than that of a medium system. It is necessary to design reasonable width in each unit. It is benefital for sewage well-distributed and saving soil as well as infiltration pipe. Then, soil in GPPLF will be better used.

\section{CONCLUSIONS}

1) To increase pollutant removal rate, it is important to 
increase the opening rate to enlarge the contact area of pipe wall, soil interface and air.

2) To increase pollutant removal rate and prevent clogging, it is conducive to improvement of aerobic environment in the soil around the infiltration pipe by keeping air circulation condition.

3) The open channel should be set up to deal with bad weather.

4) For the GPPLF to be better used, it is necessary to design a reasonable width in each unit which helps the sewage to be well-distributed.

\section{ACKNOWLEDGEMENTS}

Special thanks go to the funding by the Sichuan Province Scientific Support Plan (2009SZ0244). And the technical support of environmental engineering laboratory in Southwest University of Science and Technology is greatly appreciated.

\section{REFERENCES}

[1] Lance, J.C. and Gilbert, R.G. (1980) Renovation of wastewater by soil columns flooded with primary effluent. Water Pollution Control Federation, 52, 381-388.

[2] SFC. (2001) Gravelless and chamber systems alternative drain-field designs,” Pipeline, 12, 1-8.

[3] Cai, S.-T., Wang, C.-D., Xu, Q.-Y., Wang, X.-Y. and Li, C.-L. (2011) A study on gravel-less leach-fields with perforated pipe. Environmental Science \& Technology, 34, 98-101.

[4] Gill, L.W., O’Luanaigh, N., Johnston, P.M., Misstea, B.D.R. and O'Suilleabhain, C. (2009) nutrient loading on sub-soils from on-site wastewater effluent comparing septic tank and secondary treatment systems. Water Research, 43, 2739-2749. doi:10.1016/j.watres.2009.03.024

[5] T. K. Stevik, G. Ausland, et al. (1999) "Removal of E. coli bacteria during intermittent filtration of wastewater effluent as affected by dosing rate and media type," Water Resource, 33, 2088-2098. doi:10.1016/S0043-1354(98)00413-8

[6] Knowles, P.R., Griffin, P. and Davies, P.A. (2010) Complementary methods to investigate the development of clogging within a horizontal sub-surface flow tertiary treatment wetland,” Water Research, 44, 320-330. doi:10.1016/j.watres.2009.09.028

[7] Leverenz, H.L., Tchobanoglous, G., and Darby, J.L., (2009) Clogging in intermittently dosed sand filters used for wastewater treatment," Water Research, 43, 695-705. doi:10.1016/j.watres.2008.10.054

[8] Kim, J.-W., Choi, H. and Pachepsky, Y.A. (2010) Biofilm morphology as related to the porous media clogging. Water Research, 44, 1193-1201. doi:10.1016/j.watres.2009.05.049

[9] Kristiansen, R. (1981) Sand-filter trenches for purification of septic tank effluent: I. The clogging mechanism and soil physical environment. Journal of Environmental Quality, 10, 353-357. doi:10.2134/jeq1981.00472425001000030020x

[10] Kristiansen, R. (1981) "Sand-filter trenches for purification of septic tank effluent: II. The fate of nitrogen. Journal of Environmental Quality, 10, 353-357. doi:10.2134/jeq1981.00472425001000030020x

[11] Zhao, L.-f., Zhu, W. and Tong, W. (2009) Clogging processes caused by biofilm growth and organic particle accumulation in lab-scale vertical flow constructed wetlands," Environmental Sciences, 21, 750-757. doi:10.1016/S1001-0742(08)62336-0

[12] Kandelous, M.M. and Simunek, J. (2010) “Numerical simulations of water movement in a subsurface drip irrigation system under field and laboratory conditions using HYDRUS-2D. Agricultural Water Management, 97, 1070-1076. doi:10.1016/j.agwat.2010.02.012

[13] Garc, J., Chiva, J., Aguirre, P., Alvarez, E., Sierra, J.P. and Mujeriego, R. (2004) Hydraulic behavior of horizontal sub-surface flow constructed wetlands with different aspect ratio and granular medium size. Ecological Engineering, 23, 177-187. doi:10.1016/j.ecoleng.2004.09.002

[14] Giraldi, D., Vitturi, M. de M. and Iannelli, R. (2010) A dynamic numerical model of subsurface vertical flow constructed wetlands. Environmental Modeling \& Software, 25, 633-640. doi:10.1016/j.envsoft.2009.05.007

[15] Van Cuyk, S., Siegrist, R., Logan, A., Masson, S. et al., (2001) Hydraulic and purification behaviors and their interaction during wastewater treatment in soil infiltration systems. Water Research, 35, pp. 953-964. doi:10.1016/S0043-1354(00)00349-3 